\title{
Testis development in the vole, Microtus agrestis, subjected to long or short photoperiods from birth
}

\author{
C. Anne Grocock \\ Department of Human Anatomy, University of Oxford, South Parks Road, \\ Oxford OX1 $3 Q X, U . K$.
}

\begin{abstract}
Summary. Voles exposed to long photoperiods (16L:8D) from birth became sexually mature at 40-45 days and remained so up to the end of the experiment at 6 months of age. In short photoperiods development was inhibited up to 60 days but the majority of males became sexually mature between 4 and 6 months of age.
\end{abstract}

\section{Introduction}

Under laboratory conditions testis growth in voles is stimulated by long photoperiods. In short photoperiods, however, gonadal development is inhibited (Baker \& Ranson, 1932; Clarke \& Kennedy, 1967; Breed \& Clarke, 1970; Worth, Charlton \& MacKinnon, 1973; Grocock \& Clarke, 1974).

Most of the above experiments have involved exposing voles to long or short photoperiods for periods up to 2 months. However, Hoffmann $(1975,1978)$ has shown that, in Djungarian hamsters kept from birth in short photoperiods, testis development is initially inhibited but after several months the testes develop. In the golden hamster regression of mature testes by exposure to short photoperiods is followed by spontaneous recrudescence of the testes (Reiter, 1972; Turek, Elliot, Alvis \& Menaker, 1975; Stetson, Matt \& Watson-Whitmyre, 1976).

The following study was carried out to investigate the effects of exposing male voles to long or short photoperiods from birth to 6 months of age and in particular to see whether the testes would eventually develop after an initial inhibition in short photoperiods. The results reported here are part of a larger study in which hormone levels are being measured and the ultrastructure of the testis investigated.

\section{Materials and Methods}

Male voles were kept from birth in either long photoperiods ( $16 \mathrm{~h}$ light and $8 \mathrm{~h}$ darkness, $16 \mathrm{~L}: 8 \mathrm{D}$ ) or short photoperiods ( $8 \mathrm{~h}$ light and $16 \mathrm{~h}$ darkness, $8 \mathrm{~L}: 16 \mathrm{D})$. The parents of those animals born in short photoperiods had previously been in long photoperiods but were transferred to short photoperiods after mating. After weaning animals were kept in cages with 6 animals or less per cage.

Animals were killed every 5 days from the day of birth (Day 0 ) up to 70 days of age and thereafter at 90,105,120,140 and 180 days of age. An average of 12 (range 5-29) animals were killed at each point. Testes and seminal vesicles were dissected out after death and weighed. Animals were bled before death and the blood used for hormone assays, the results of which will be reported elsewhere. The testes were fixed in Bouin's fluid prior to embedding in paraffin wax for routine histology. These sections were stained with haematoxylin and eosin. The other testis was fixed in glutaraldehyde for embedding in Araldite for further analysis by electron microscopy. Semi-thin sections of these testes were stained with toluidine blue. The normal 
method of counting cells at a particular stage of spermatogenesis (Oakberg, 1956) is not feasible during development because until spermatogenesis is complete the individual stages are not distinguishable and direct comparisons are difficult to make. Cell counts were possible before the wave of spermatogenesis was established and were carried out at Days 0 and 5 on 10 tubular cross-sections per animal. All counts were corrected for differences in nuclear diameter by an adaptation of Abercrombie's formula (Swierstra \& Foote, 1963) and statistical analysis was carried out using Students $t$ test.

Mating tests were carried out with 13 males which had been born in short photoperiods to determine the age at which they first became fertile and how long their fertility lasted.

\section{Results}

\section{Weights}

Body, testis and seminal vesicle weights are shown in Text-fig. 1. Body weight showed a similar increase in animals kept in both long and short photoperiods. Testis weight was, however, markedly different in the two groups with a sharp increase in weight in the long photoperiod animals, whereas in short photoperiods testis weight remained low until 60 days, when it began to increase to reach a mean weight of $300 \mathrm{mg}$ by 180 days. This was still well below the mean testis weight in long photoperiods. Seminal vesicle weights, although showing more variation, followed the same pattern.

\section{Histology: long days}

Days $0-5$. Sex cords were obvious in the testis and contain a ring of supporting cell nuclei with gonocytes in the centre (Pl. 1, Figs 1 and 2). Gonocyte numbers were significantly reduced by Day 5 (see Table 1). No lumen was present. Interstitial cells were present but the nuclei were elongated and there was very little cytoplasm.

Days 10-15. Spermatogonial divisions could be observed at Day 10 and by Day 15 primary spermatocytes were present (Pl. 1, Fig. 3), although not all tubules showed the same stage of development, i.e. the wave of spermatogenesis was already established. In some tubules a lumen appeared in the centre. Interstitial cells were beginning to show some development with the nuclei becoming more rounded, but there was still little development of the cytoplasm.

Days 20-35. At Day 20 two generations of primary spermatocytes appeared in many tubules and most tubules had a lumen. Round spermatids first appeared at Day 25 (Pl. 1, Fig. 4) and elongated spermatids at Day 30. By Day 35 spermatogenesis was complete although spermatozoa were not produced in large numbers (Pl. 2, Fig. 6).

\section{EXPLANATION OF PLATE 1}

Semi-thin Araldite sections of vole testes stained with toluidine blue. The magnification is shown by the scale bar $=30 \mu \mathrm{M}$ in Fig. 1 .

Fig. 1. Day 0 in $16 \mathrm{~L}: 8 \mathrm{D}$. Gonocytes $(\mathrm{G})$ and supporting cells $(\mathrm{S})$ can be seen in the sex cords.

Fig. 2. Day 5 in $16 \mathrm{~L}: 8 \mathrm{D}$. Gonocytes $(G)$ are reduced in numbers and some are still central in position although others have moved outwards. Supporting cell (S) nuclei remain near the periphery of the tubule.

Fig. 3. Day 15 in $16 \mathrm{~L}: 8 \mathrm{D}$. Primary spermatocytes (P) are first seen at this age. Not all tubule cross-sections are at the same stage of development.

Fig. 4. Day 25 in $16 \mathrm{~L}: 8 \mathrm{D}$. Round spermatids $(R)$ can be seen in some tubules and the interstitial tissue (IC) has become more obvious.

Fig. 5. Day 25 in $8 \mathrm{~L}: 16 \mathrm{D}$. In contrast to the appearance in long photoperiods no lumen has yet appeared and primary spermatocytes $(\mathrm{P})$ are the most advanced cells present. 


\section{PLATE 1}
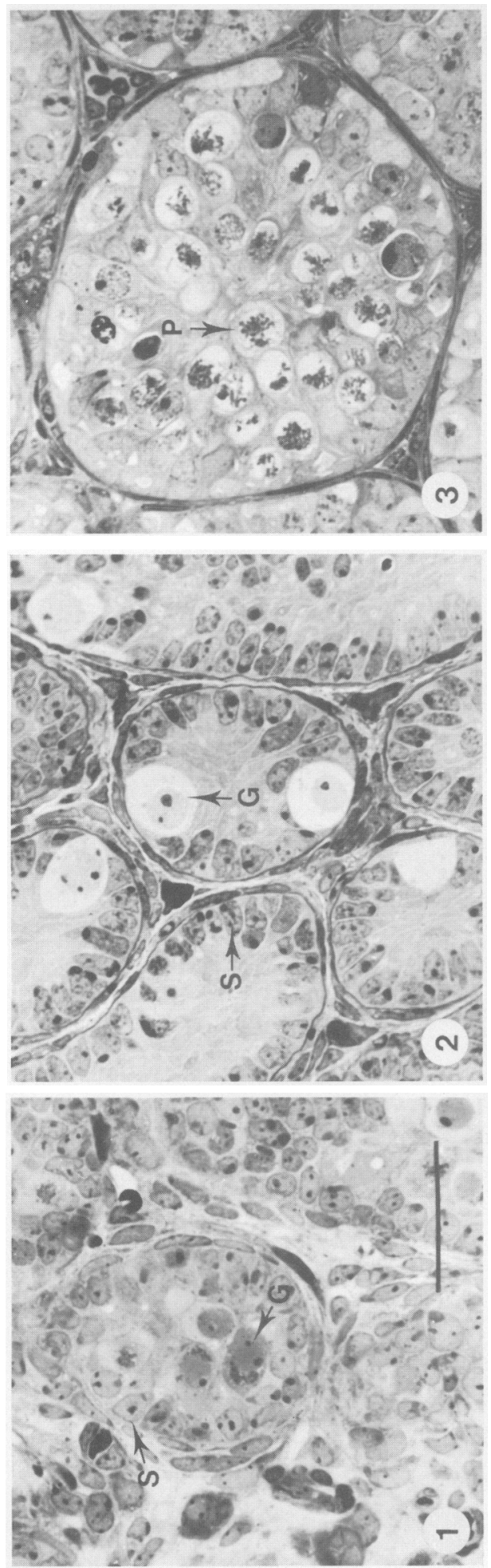
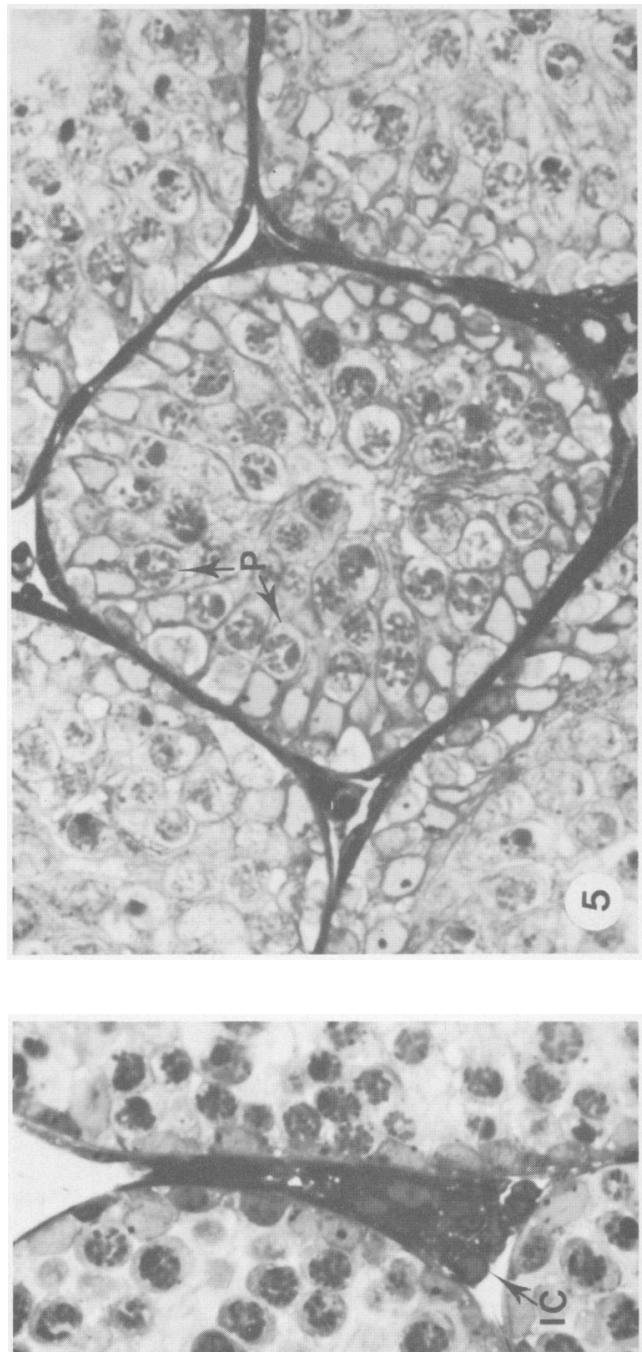

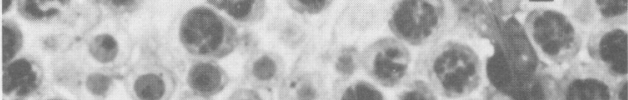

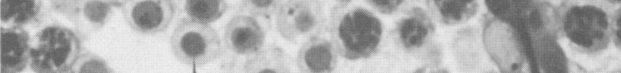

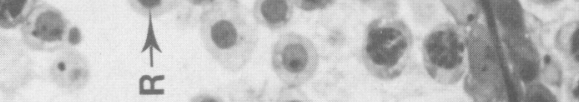

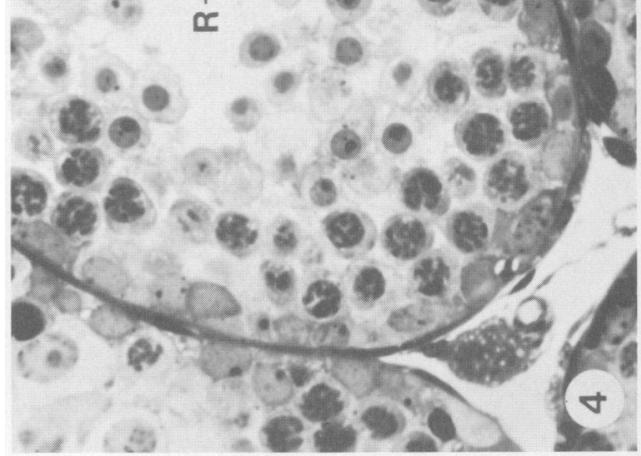




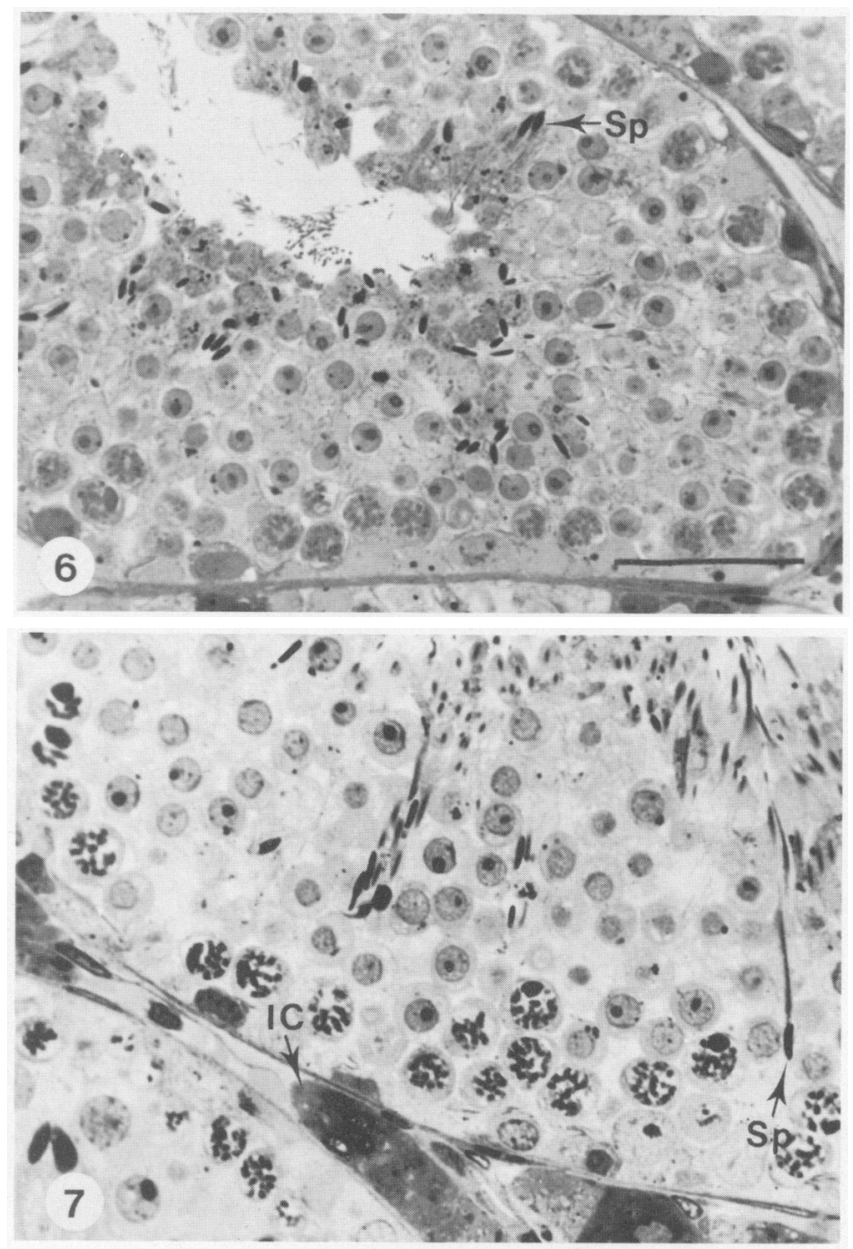

\section{PLATE 2}

Semi-thin Araldite sections of vole testes stained with toluidine blue. The magnification is shown by the scale bar $=30 \mu \mathrm{M}$ in Fig. 6 .

Fig. 6. Day 35 in $16 \mathrm{~L}: 8 \mathrm{D}$. Although spermatozoa $(\mathrm{Sp})$ are produced at this age, animals are not fertile until 6 weeks of age.

Fig. 7. Day 120 in $16 \mathrm{~L}: 8 \mathrm{D}$. Full spermatogenesis is still present at 4 months of age and the testis shows no sign of spontaneous regression. $\mathrm{Sp}=$ spermatozoa; $\mathrm{IC}=$ interstitial cells. 


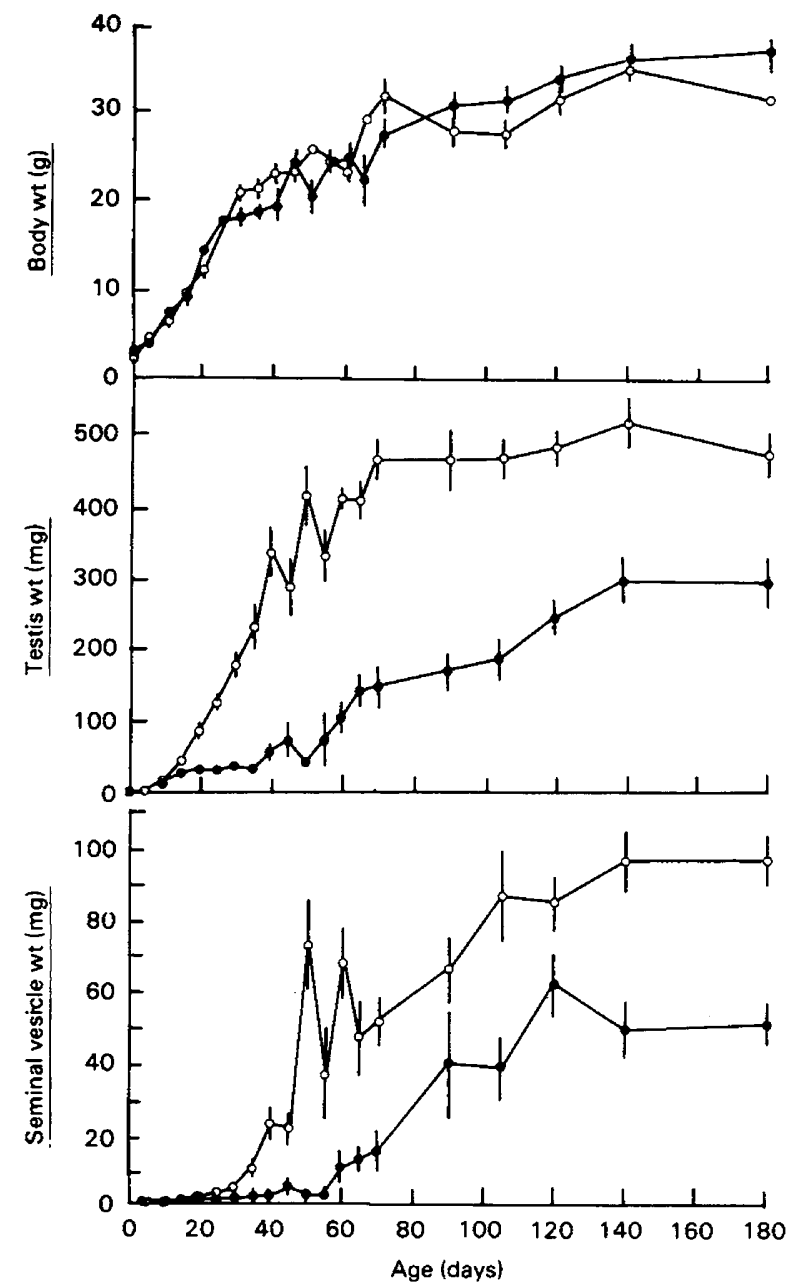

Text-fig. 1. Mean ( \pm s.e.m.) body, testis and seminal vesicle weights of male voles kept in long $(16 \mathrm{~L}: 8 \mathrm{D}, \mathrm{O})$ or short $(8 \mathrm{~L}: 16 \mathrm{D}, 0)$ photoperiods from birth to 6 months of age. There was an average of 12 (range 5-29) animals at each point.

Day 35 onwards. Once full spermatogenesis was established, there was an increase in testis weight which became stable after 70 days. Examination of the cauda epididymidis and vas deferens showed that large numbers of spermatozoa were present at 40 days and later.

$\mathrm{Up}$ to the age of 6 months, no decline in spermatogenesis was seen when animals were maintained in long photoperiods (Pl. 2, Fig. 7).

\section{Histology: short days}

Days 0-15. The appearance of the testis and the changes which occurred were similar to those in long days. Gonocyte numbers were again reduced at Day 5 and there was a slight increase in supporting cell numbers. It was only after this time that obvious differences between the two treatments could be observed.

Days 20-60. There was considerable variation in the degree of development of individual animals. However, the majority of animals had only one or two generations of primary spermatocytes in their testes. Occasionally round spermatids occurred. Frequently the tubules contained signs of germ cell degeneration with multinucleate masses appearing in the lumen. 
Table 1. Mean ( \pm s.e.m.) numbers of gonocyte and supporting cell nuclei per cross-section of seminiferous tubule in 0 - and 5-day-old male voles born in long or short photoperiods

\begin{tabular}{ccccc}
\hline Light treatment & Age (days) & $\begin{array}{c}\text { No. of } \\
\text { voles }\end{array}$ & $\begin{array}{c}\text { No. of } \\
\text { gonocytes/tubule } \\
\text { cross-section } \dagger\end{array}$ & $\begin{array}{c}\text { No. of supporting } \\
\text { cells/tubule } \\
\text { cross-section } \dagger\end{array}$ \\
\hline 16L:8D & 0 & 7 & $2 \cdot 7 \pm 0.2$ & $10.5 \pm 0.4$ \\
& 5 & 7 & $1.6 \pm 0.1^{* *}$ & $10.6 \pm 0.4$ \\
8L: 16D & 0 & 7 & $2 \cdot 6 \pm 0.1$ & $10.8 \pm 0.3$ \\
& 5 & 7 & $1.8 \pm 0.2^{* *}$ & $11.7 \pm 0.3^{*}$ \\
\hline
\end{tabular}

Values significantly different from those at 0 days. ${ }^{*} P<0.05 ;{ }^{* *} P<0.001$.

$\dagger 10$ cross-sections counted per animal.

Some tubules also had whole generations of cells missing, particularly the early primary spermatocytes, while still retaining a central layer of more advanced cells, e.g. round spermatids. These observations indicate a certain amount of 'regression' of the epithelium of such animals.

Days 60-180. After Day 60 there was a general increase in spermatogenic activity and in the majority of animals spermatids and spermatozoa develop. There was considerable individual variation in the time taken to achieve full spermatogenesis but most animals achieved this between 4 and 6 months of age.

\section{Mating tests}

These showed that all but one of the 13 males became fertile in an average of 5 months. Two of the males became fertile, i.e. their females produced litters, at 3 months of age but 5 other males did not become fertile until 6-8 months old. With the exception of the one male who has not been proved fertile, the remaining 6 males, now 12 months old, are still fertile.

\section{Discussion}

Testis development in the vole in long photoperiods is rapid and full sexual maturity is reached by 6-7 weeks. Observations on testis structure and the presence of spermatozoa in the cauda epididymidis and vas deferens confirm this. After this time the testis increased in weight to a plateau at approximately 70 days. Up to 6 months the testes remain fully active and no spontaneous regression was observed.

As has been shown in the golden and Djungarian hamsters (Reiter, 1972; Turek et al., 1975; Hoffmann, 1975; Stetson et al., 1976) testis development is not completely inhibited in short photoperiods. However, in the vole, development is much slower than in long photoperiods once it begins. Although most males became fertile after 6 months, testis weight was not as great as in animals of the same age kept in long photoperiods. Mating tests with a small number of animals which have developed in short photoperiods, show that the males remain fertile, even up to 1 year old. These males were mated with females which had similarly been born in short photoperiods and these pairs, maintained in short photoperiods, produced first litters at 3-8 months of age.

The spontaneous development of the testis in short photoperiods may be part of the normal mechanism of development in the breeding cycle of the vole (Microtus agrestis) in the field. Male voles in the field become sexually mature before the spring equinox when daylength is shorter than a stimulatory photoperiod in the laboratory (Grocock \& Charlton, 1976). It is possible that these males, born the previous season, may develop during December to February, not because 
of some positive environmental stimulus such as daylength or food, but because they spontaneously develop after being in an inhibitory photoperiod for several months.

I should like to thank Miss S. Collins and Mr G. Ferrick for their technical assistance. The work was supported by grants from the Agricultural Research Council and the Medical Research Council.

\section{References}

Baker, J.R. \& Ranson, R.M. (1932) Factors affecting the breeding of the field mouse (Microtus agrestis). Part 1. Light. Proc. $R$. Soc. B 110, 313-322.

Breed, W.G. \& Clarke, J.R. (1970) Effect of photoperiod on ovarian function in the vole, Microtus agrestis. J. Reprod. Fert. 23, 189-192.

Clarke, J.R. \& Kennedy, J.P. (1967) Effect of light and temperature upon gonad activity in the vole (Microtus agrestis). Gen. comp. Endocr. 8, 474-488.

Grocock, C. \& Clarke, J.R. (1974) Photoperiodic control of testis activity in the vole, Microtus agrestis. $J$. Reprod. Fert. 39, 337-347.

Grocock, C.A. \& Charlton, H.M. (1976) Seasonal changes in testis activity in the vole, Microtus agrestis. 1. Light microscopic autoradiography. Gen. comp. Endocr. 29, Abstr. 108.

Hoffmann, K. (1975) Photoperiod influences age of puberty in the Djungarian hamster, Phodopus sungorus. Pflügers Arch. Eur. J. Physiol. 359, Suppl. R, 144, Abstr. 288.

Hoffmann, K. (1978) Effects of short photoperiods on puberty, growth and moult in the Djungarian hamster (Phodopus sungorus). J. Reprod. Fert. 54, 29-35.

Oakberg, E.F. (1956) A description of spermiogenesis in the mouse and its use in analysis of the cycle of the seminiferous epithelium and germ cell renewal. $\mathrm{Am}$. J. Anat. 99, 391-413.

Reiter, R.J. (1972) Evidence for refractoriness of the pituitary-gonadal axis to the pineal gland in golden hamsters and to possible implications in annual reproductive rhythms. Anat. Rec. 173, 365-371.

Stetson, M.H., Matt, K.S. \& Watson-Whitmyre, M. (1976) Photoperiodism and reproduction in golden hamsters: circadian organization and the termination of photorefractionness. Biol. Reprod. 14, 531-537.

Swierstra, E.E. \& Foote, R.H. (1963) Cytology and kinetics of spermatogenesis in the rabbit. $J$. Reprod. Fert. 5, 309-322.

Turek, F.W., Elliot, J.A., Alvis, J.D. \& Menaker, M. (1975) Effect of prolonged exposure to nonstimulatory photoperiods on the activity of the neuroendocrine testicular axis of golden hamsters. Biol. Reprod. 13, 475-481.

Worth, R.W., Charlton, H.M. \& MacKinnon, P.C.B. (1973) Field and laboratory studies on the control of luteinizing hormone secretion and gonadal activity in the vole, Microtus agrestis. J. Reprod. Fert., Suppl. 19, 89-99. 